\title{
Basigin expression and hormonal regulation in the rat uterus during the peri-implantation period
}

\author{
L-J. Xiao ${ }^{1}$, H-L. Diao ${ }^{1}$, X-H. Ma¹, N-Z. Ding ${ }^{1}$, K. Kadomatsu², \\ T. Muramatsu ${ }^{2}$ and Z-M. Yang ${ }^{1 *}$ \\ ${ }^{1}$ College of Life Science, Northeast Agricultural University, Harbin 150030, China; and \\ ${ }^{2}$ Department of Biochemistry, Nagoya University School of Medicine, 65 Tsurumai-cho, \\ Showa-ku, Nagoya 466, Japan
}

\begin{abstract}
Basigin is essential for fertilization and implantation. The aim of this study was to determine the expression and hormonal regulation of the basigin gene in the rat uterus during the peri-implantation period. Basigin mRNA was localized strongly in the luminal epithelium on day 1 of pregnancy and gradually decreased to a basal concentration from day 3 to day 5 of pregnancy. Basigin mRNA and protein were expressed strongly in the implanting blastocyst and primary decidua on day 6 of pregnancy. A similar expression pattern was also induced in the uterus after delayed implantation was terminated by oestrogen treat-
\end{abstract}

\section{Introduction}

Basigin, a highly glycosylated transmembrane protein, belongs to the immunoglobulin superfamily with two immunoglobulin domains (Miyauchi et al., 1990). Basigin has been identified independently by several groups and given different names: HT7, neurothelin and 5A11 in chickens; gp42 in mice; OX-47 and CE9 in rats; and M6 and EMMPRIN in humans (for a review, see Igakura et al., 1998). Basigin expression in mouse endometrium was stronger at sites with embryos in the lumen than at sites without embryos (Kuno et al., 1998). Basigin mRNA was expressed strongly in the inner cell mass and embryo on days 4.0-7.5 (Igakura et al., 1998). Basigin (-/-) mouse embryos developed normally during preimplantation stages; however, most of these embryos died at about the time of implantation. Many null mutant embryos were lost because of deficiencies in implantation. Surviving male and female mice with basigin deficiency were sterile (Igakura et al., 1998). The expression and regulation of the basigin gene in the uterus of other mammalian species during early pregnancy has not been studied.

The aim of the present study was to determine whether basigin is essential for embryo implantation in mammalian species other than mice. In situ hybridization and immunohistochemistry were used to examine the expression of the

*Correspondence

Email: zmyang@mail.neau.edu.cn ment and the embryo implanted, whereas expression was not detected during delayed implantation. Basigin expression was not detected on day 6 of pseudopregnancy. Basigin mRNA was expressed strongly in the decidua on days 7 and 8 of pregnancy. Furthermore, both basigin mRNA and protein were induced in the decidua during artificial decidualization. In addition, oestrogen stimulated strong expression of basigin mRNA in the uterine epithelium of ovariectomized rats. These findings indicate that basigin may play a role during implantation and decidualization in rats.

basigin gene in the rat uterus during early pregnancy and pseudopregnancy, delayed implantation and artificial decidualization, and also its regulation by steroid hormones.

\section{Materials and Methods}

\section{Animals and treatments}

Mature Sprague-Dawley rats were maintained in cages in a controlled environment with a $14 \mathrm{~h}$ light:10 h dark photoperiod. All animal procedures were approved by the Institutional Animal Care and Use Committee of the Northeast Agricultural University. The stage of the oestrous cycle was determined by inspection of vaginal smears. Adult females were mated with fertile males of the same strain to induce pregnancy. Pregnancy was confirmed by examining for the presence of spermatozoa in the vaginal smear (day $1=$ day of vaginal smear positive for spermatozoa). On days $1-5$, pregnancy was confirmed by flushing embryos from the reproductive tracts. On days $6-7$, the implantation sites were identified by i.v. injection of $0.1 \mathrm{ml}$ of $1 \%(\mathrm{w} / \mathrm{v})$ trypan blue solution in $0.85 \%(\mathrm{w} / \mathrm{v}) \mathrm{NaCl}$. Pseudopregnancy was induced by caging adult females with vasectomized males and was confirmed by checking for a vaginal plug (either in the vagina or on the cage floor) the next morning. At least three rats were used in each stage or treatment in this study.

Hormonal treatments were initiated 2 weeks after mature female rats were ovariectomized. The ovariectomized rats were treated with an injection of oestradiol (250 ng per rat; 

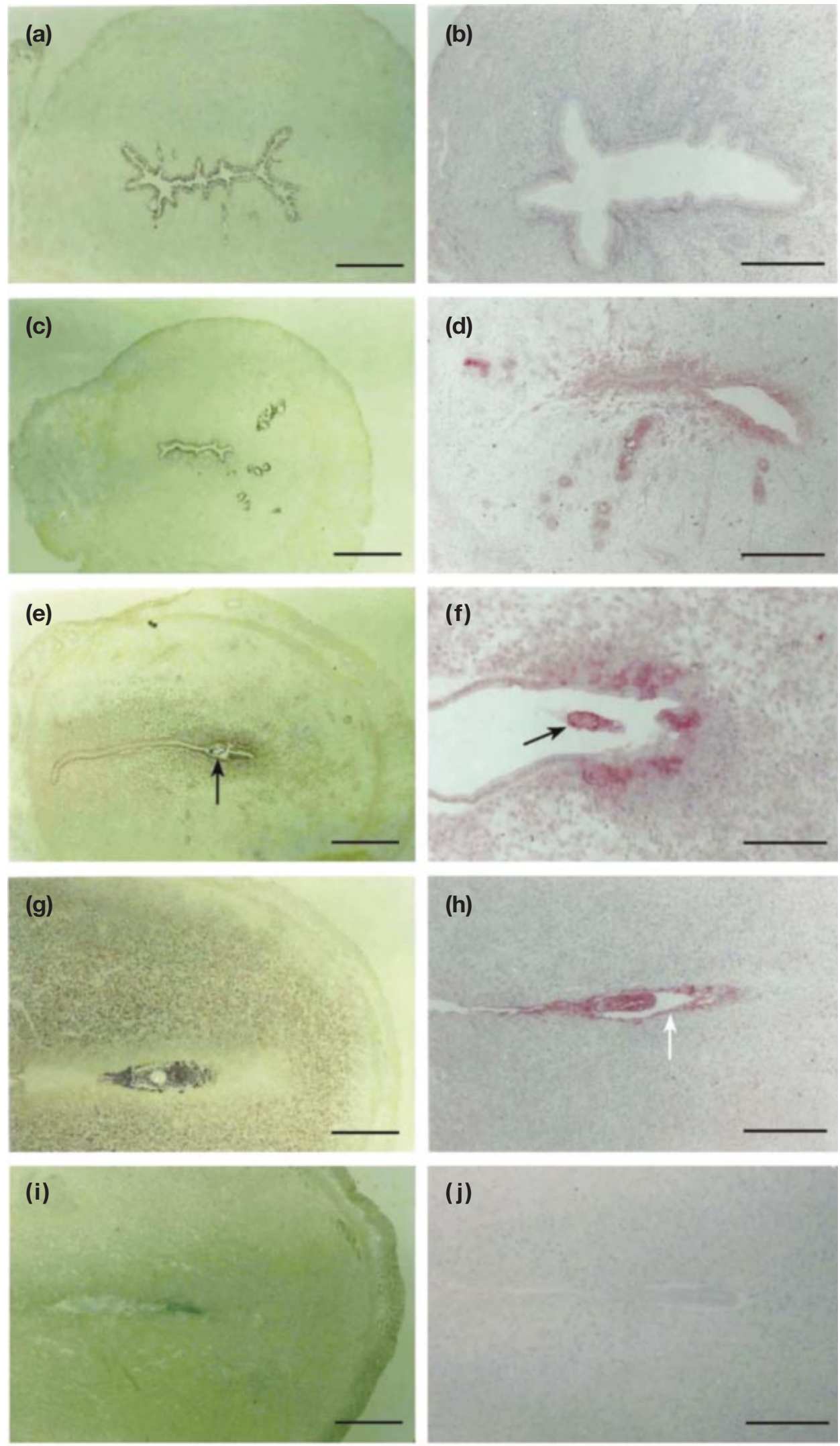

Fig. 1. In situ hybridization (left panels) and immunohistochemistry (right panels) of basigin gene in rat uterus on $(\mathrm{a}, \mathrm{b})$ day $1,(\mathrm{c}, \mathrm{d})$ day $5,(\mathrm{e}, \mathrm{f})$ day 6 and $(\mathrm{g}, \mathrm{h})$ day 8 of pregnancy, respectively. (i) Basigin 
Sigma Chemical Co., St Louis, MO), progesterone (4 mg per rat; Sigma), or a combination of the same doses of progesterone and oestradiol. All steroids were dissolved in sesame oil and injected s.c. Controls received vehicle only $(0.2 \mathrm{ml}$ per rat). Treated rats were killed $24 \mathrm{~h}$ later.

For induction of delayed implantation, pregnant rats were treated with progesterone (5 $\mathrm{mg}$ per rat, s.c.) on day 4 of pregnancy and ovariectomized at 08:30-09:00 h. Progesterone ( $5 \mathrm{mg}$ per rat) was injected to maintain delayed implantation from day 5 to day 7 . Delayed implantation in the progesterone-primed rats was terminated by administration of oestrogen (250 ng per rat). The rats were killed by stunning and cervical dislocation at $24 \mathrm{~h}$ after oestrogen treatment and uteri were collected. The implantation sites were identified by i.v. injection of trypan blue solution into the tail.

\section{Artificial decidualization}

Mature female rats were ovariectomized and were sensitized for the decidual cell reaction 5 days later according to the procedures described by Kennedy and Ross (1997). Some of the rats were administered with a bilateral intrauterine injection of $100 \mu \mathrm{l}$ sesame oil at about 12:00 h on the equivalent of day 5 of pseudopregnancy. The animals that did not receive the intrauterine injection served as non-stimulated controls (Orlando-Mathur et al., 1996). Treated rats were killed 6 days after the intrauterine injection of oil.

\section{Immunohistochemistry}

Uteri were fixed immediately in Bouin's solution for $24 \mathrm{~h}$ and embedded in paraffin wax. After the sections $(7 \mu \mathrm{m})$ were cut, the paraffin wax was removed and the sections were rehydrated. Antigen retrieval was performed by incu-

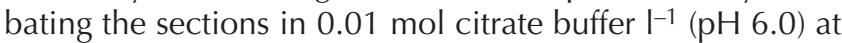
$95^{\circ} \mathrm{C}$ for $10 \mathrm{~min}$ and by cooling at room temperature for 20 min. Non-specific binding was blocked with 10\% (v/v) normal horse serum in PBS for $1 \mathrm{~h}$. The sections were incubated with rabbit anti-mouse basigin IgG in 10\% (v/v) horse serum (1:100) for $1 \mathrm{~h}$. The anti-basigin antibodies had been raised against a glutathione-S-transferase-basigin fusion protein containing the whole extracellular domain of mouse basigin (Fan et al., 1998). The sections were then incubated with biotinylated secondary antibody followed by an avidin-alkaline phosphatase complex and Vector Red, according to the manufacturer's protocol (Vectastain ABC-AP kit; Vector Laboratories, Burlingame, CA). Endogenous alkaline phosphatase activity was inhibited by supplementing $1 \mathrm{mmol}$ levamisole $\mathrm{I}^{-1}$ (Sigma) into Vector Red substrate solution. Moreover, rabbit anti-mouse basigin IgG was replaced with the same concentration of normal rabbit IgG as a negative control. The sections were counter- stained with haematoxylin and mounted. The degree of staining was assessed subjectively by blind examination of the slides by two investigators.

\section{In situ hybridization}

A 553 bp rat basigin cDNA fragment was reverse transcribed and amplified with the total RNA from rat uterus using forward primer 5'-CGGAATTCCGGAACACGCCAGTGAGG and reverse primer 5'-GCGGATCCACAGGAGTGGAGGCAGACG, designed according to the rat basigin cDNA sequence (556-1108 bp, Genebank accession number X54640). Within these primers, an EcoRI site was added at the $5^{\prime}$ end of the forward primer and a BamH1 site at the 5' end of the reverse primer. The PCR fragment for rat basigin was recovered from the agarose gel and cloned into pGEM$3 \mathrm{Zf}(+)$ plasmid through ECoRI and BamH1 sites, respectively. The cloned rat basigin fragment was verified further by sequencing. These plasmids were linearized with enzymes for labelling. Digoxigenin-labelled antisense or sense cRNA probes were transcribed in vitro using a digoxigenin RNA labelling kit (T7 for sense, SP6 for antisense; Boehringer Mannheim, Mannheim).

Uteri were cut into pieces of $4-6 \mathrm{~mm}$ and flash frozen in liquid nitrogen. Frozen sections $(10 \mu \mathrm{m})$ were mounted on slides coated with 3-aminopropyltriethoxy-silane (Sigma) and fixed in $4 \%(\mathrm{w} / \mathrm{v})$ paraformaldehyde solution in PBS. The sections were treated in $0.2 \mathrm{~mol} \mathrm{HCl} \mathrm{I}^{-1}$ for 10 min after two washes in PBS, digested with $0.1 \mu \mathrm{g}$ proteinase $\mathrm{K} \mathrm{ml}^{-1}$ at room temperature for 10-15 $\mathrm{min}$ and incubated $(2 \times 5 \mathrm{~min})$ in $0.2 \%(\mathrm{w} / \mathrm{v})$ glycine in PBS. The sections were post-fixed in $4 \%(\mathrm{w} / \mathrm{v})$ paraformaldehyde for $2 \mathrm{~min}$. After acetylation in freshly prepared $0.25 \%(\mathrm{w} / \mathrm{v})$ acetic anhydride in $0.1 \mathrm{~mol}$ triethanolamine $\mathrm{I}^{-1}(\mathrm{pH} \mathrm{8.0)}$ for $10 \mathrm{~min}$, the sections were washed $(2 \times 5 \mathrm{~min})$ in $2 \times$ SSC $(1 \times$ SSC: 0.15 mol sodium chloride $\mathrm{I}^{-1}, 0.015$ mol sodium citrate $\mathrm{I}^{-1}$ ), dehydrated in serial dilutions of ethanol and air dried. After prehybridization in hybridization buffer $(4 \times$ SSC, $50 \%$ $(\mathrm{v} / \mathrm{v})$ formamide, 5\% (w/v) dextran sulphate, $1 \times$ Denhardt's solution, $0.5 \mathrm{mg}$ denatured salmon sperm DNA ml-1, 0.25 mg yeast tRNA ml-1) at $25^{\circ} \mathrm{C}$ for $2-3 \mathrm{~h}$, the sections were hybridized in hybridization buffer with $1-5 \mu \mathrm{g} \mathrm{ml} \mathrm{m}^{-1}$ of digoxigenin-labelled antisense or sense RNA probe for rat basigin at $49^{\circ} \mathrm{C}$ for $16 \mathrm{~h}$. After hybridization, the sections were washed in $4 \times$ SSC at room temperature for $10 \mathrm{~min}$ and digested in $10 \mu \mathrm{g}$ RNase $\mathrm{A} \mathrm{ml}^{-1}$ (Boehringer Mannheim) in $0.01 \mathrm{~mol}^{\mathrm{T}}$ ris- $\mathrm{HCl} \mathrm{I}-1$ and $0.5 \mathrm{~mol} \mathrm{NaCl} \mathrm{I}^{-1}(\mathrm{pH} \mathrm{8.0)}$ at $37^{\circ} \mathrm{C}$ for $30 \mathrm{~min}$. The sections were washed in $4 \times \mathrm{SSC}$, $1 \times$ SSC and $0.5 \times$ SSC $(2 \times 10 \mathrm{~min}$ each $)$ at $42^{\circ} \mathrm{C}$. After non-specific binding was blocked with $0.5 \%(\mathrm{w} / \mathrm{v})$ block mix (Boehringer Mannheim), the sections were incubated in sheep anti-digoxigenin antibody conjugated to alkaline phosphatase (1:200; Boehringer Mannheim). The signal

mRNA signal was not observed in the rat uterus on day 8 of pregnancy when basigin sense cRNA probe was used. (j) Basigin immunostaining was not observed in the rat uterus on day 8 of pregnancy when rabbit anti-basigin antibody was replaced with normal rabbit IgG. Black arrow: implanting blastocyst; white arrow: luminal epithelium. Scale bars represent $25 \mu \mathrm{m}$. 

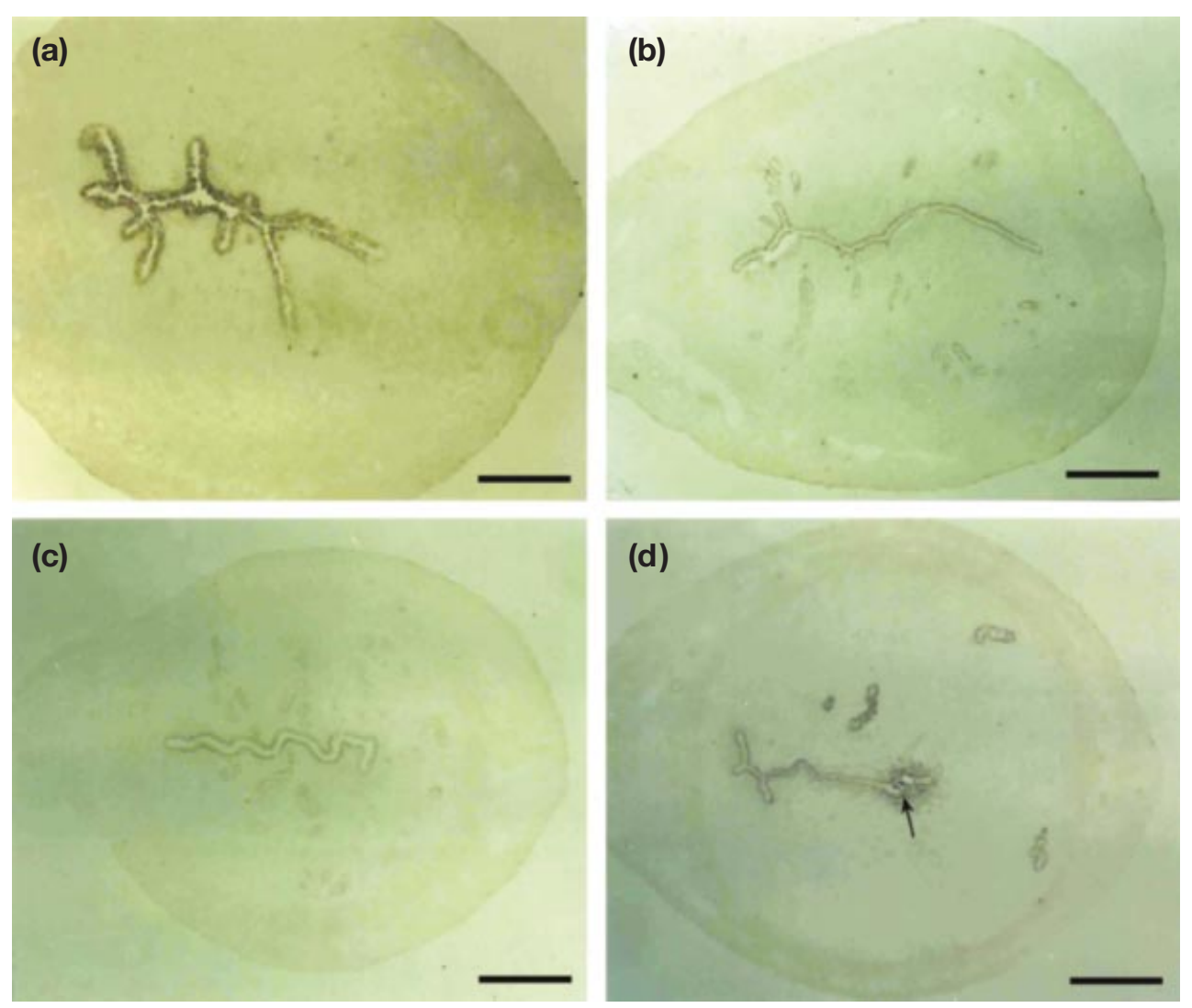

Fig. 2. In situ hybridization of basigin mRNA in rat uterus. (a) Basigin mRNA was detected strongly in the luminal epithelium on day 1 of pseudopregnancy, but (b) expression was very low in the luminal and glandular epithelia on day 6 of pseudopregnancy. (c) Basal expression of basigin mRNA was observed in the luminal epithelium during delayed implantation. (d) When delayed implantation was terminated by oestrogen treatment and embryos implanted, basigin expression was induced significantly in the implanting blastocyst (arrow) and in the luminal and glandular epithelia at the implantation site. Scale bars represent $25 \mu \mathrm{m}$.

was visualized with $0.4 \mathrm{mmol} 5$-bromo-4-chloro-3-indolyl phosphate $\mathrm{I}^{-1}$ and $0.4 \mathrm{mmol}$ nitroblue tetrazolium $\mathrm{I}^{-1}$ in the buffer containing $100 \mathrm{mmol}$ Tris- $-\mathrm{HCl} \mathrm{l^{-1 }}(\mathrm{pH}$ 9.5), $100 \mathrm{mmol} \mathrm{NaCl} \mathrm{^{-1 }}$ and $50 \mathrm{mmol} \mathrm{MgCl}_{2} \mathrm{I}^{-1}$. Endogenous alkaline phosphatase activity was inhibited with $1 \mathrm{mmol}$ levamisole $\mathrm{I}^{-1}$ (Sigma). All of the sections were counterstained with $1 \%(\mathrm{w} / \mathrm{v})$ methyl green in $0.12 \mathrm{~mol}$ glacial acetic acid $\mathrm{l}^{-1}$ and 0.08 mol sodium acetate $\mathrm{l}^{-1}$ for $30 \mathrm{~min}$.

\section{Results}

\section{Basigin expression during early pregnancy}

Basigin mRNA was localized mainly in the luminal epithelium on day 1 of pregnancy (Fig. 1a). The amount of basigin mRNA in the luminal epithelium gradually decreased from day 2 of pregnancy and was low on days 3-5 of pregnancy (Fig. 1c). However, an intermediate amount of basigin mRNA was first detected in the glandular epithelium on day 3 of pregnancy and was maintained throughout days 4 and 5 of pregnancy. On day 6 , basigin mRNA was detected mainly in the implanting blastocyst and in the luminal epithelium surrounding the blastocyst (Fig. 1e). From day 7 to day 8 of pregnancy, basigin mRNA signal gradually increased and was detected strongly in the embryos and decidualized cells (Fig. 1g). When digoxigenin-labelled basigin antisense cRNA was replaced by digoxigenin-labelled basigin sense cRNA as a probe, no basigin mRNA signal was observed in the uterus on day 8 of pregnancy (Fig. 1i).

Basigin protein was barely detectable in the uterus on day 1 (Fig. 1b). A small amount of basigin protein appeared in the luminal epithelium on day 3 and the amount increased gradually from day 4 to day 5 . On day 5 , basigin protein was detected strongly in the glandular epithelium, luminal epithelium and underlying stromal cells (Fig. 1d). On day 6, basigin mRNA signal was observed mainly in the implanting blastocyst and sub-luminal stromal cells at the implantation site (Fig. 1f). From day 7 to day 8 , basigin protein was detected strongly in the embryos and the luminal epithelium at the implantation site (Fig. 1h). However, basigin immunostaining was not observed in the rat 

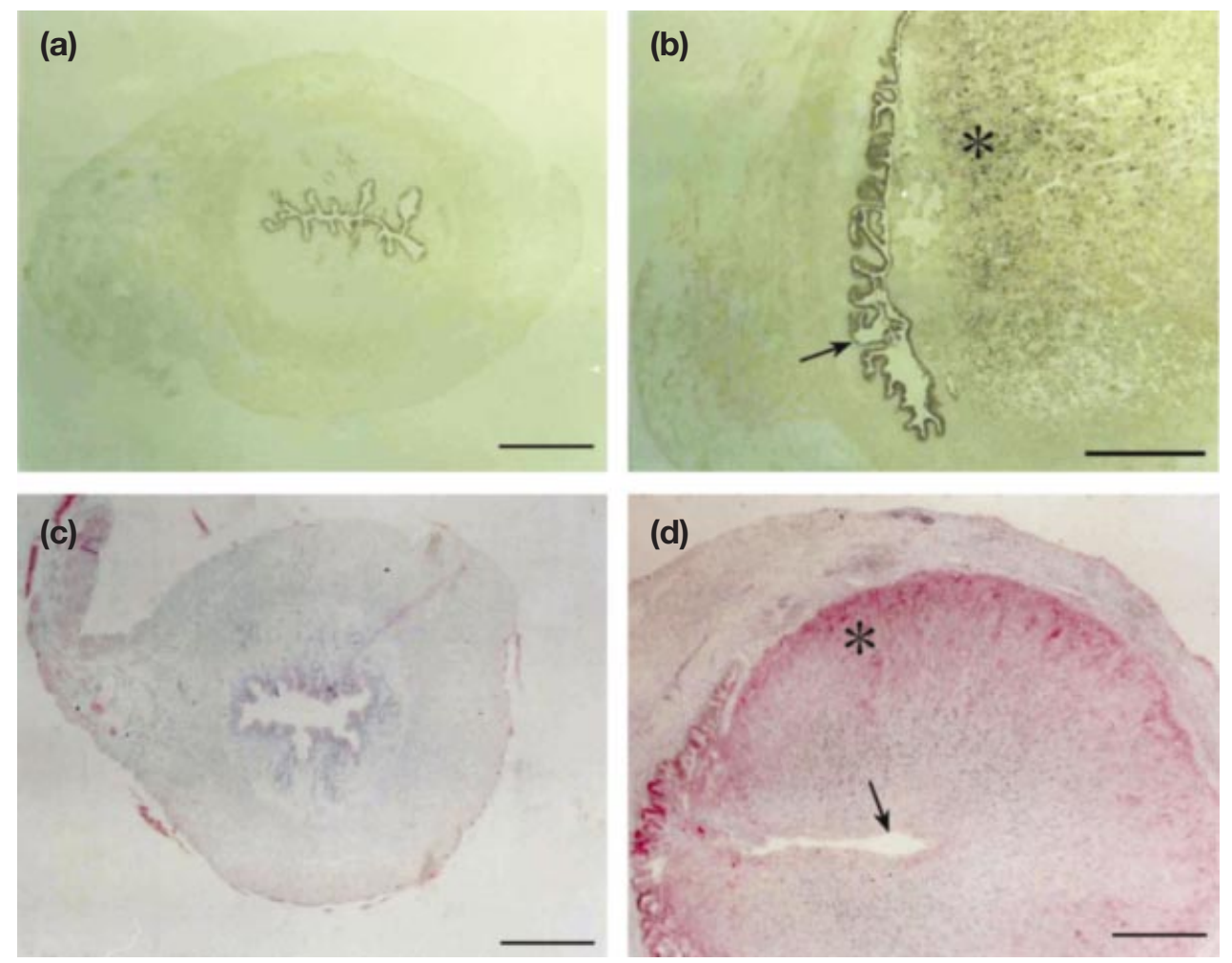

Fig. 3. Basigin expression in the rat uterus during artificial decidualization. (a) Low expression of basigin was observed in only the luminal epithelium in the uterus of control rats, whereas (b) basigin mRNA was detected strongly in the decidualized cells $\left(^{*}\right)$ and luminal epithelium (arrow) during artificial decidualization. (c) Basigin protein was barely detectable in the luminal epithelium in the uterus of control rats, but (d) was induced strongly in the decidualized cells $\left(^{*}\right)$ and luminal epithelium (arrow) during artificial decidualization. Scale bars represent $25 \mu \mathrm{m}$.

uterus on day 8 of pregnancy when rabbit anti-mouse basigin antibody was replaced with normal rabbit lgG (Fig. 1j).

\section{Basigin expression during pseudopregnancy}

During pseudopregnancy, basigin mRNA was localized strongly in the luminal epithelium on day 1 , decreased from day 2 and reached a low concentration that was maintained from day 3 to day 8 (Fig. 2a,b). Basigin mRNA was not observed in the glandular epithelium on day 1 , but a basal amount was present in the glandular epithelium from day 2 to day 8 of pseudopregnancy (Fig. 2a,b).

\section{Basigin expression during delayed implantation}

During delayed implantation, a basal amount of basigin mRNA was present in the uterus (Fig. 2c). After delayed implantation was terminated by oestrogen treatment and embryos implanted, basigin mRNA signal was induced strongly in the implanting blastocyst and outlining luminal epithelium, and glandular epithelium. A small amount of basigin mRNA was also detected in the sub-luminal stroma (Fig. 2d).

\section{Basigin expression during artificial decidualization}

A small amount of basigin mRNA was detected in the luminal epithelium in only the control uninjected uterine horn (Fig. 3a), whereas basigin mRNA was detected strongly in the luminal epithelium and decidualized stromal cells during artificial decidualization (Fig. 3b).

When decidualization was induced in the uterine horn by injecting sesame oil into the uterine lumen, basigin protein was detected strongly in the decidualized cells (Fig. $3 d$ ), whereas only a basal amount of basigin protein was observed in the control horn (Fig. 3c).

\section{Hormonal regulation of basigin expression}

A hybridization signal was not observed in the uterus of ovariectomized rats (Fig. 4a). A small amount of basigin mRNA was detected after progesterone treatment (Fig. 4b). Compared with progesterone treatment, oestrogen induced a significant increase in basigin mRNA signal in the luminal epithelium and glandular epithelium (Fig. 4c). A combination of oestradiol and progesterone stimulated a similar expression pattern as that induced by oestrogen treatment. 

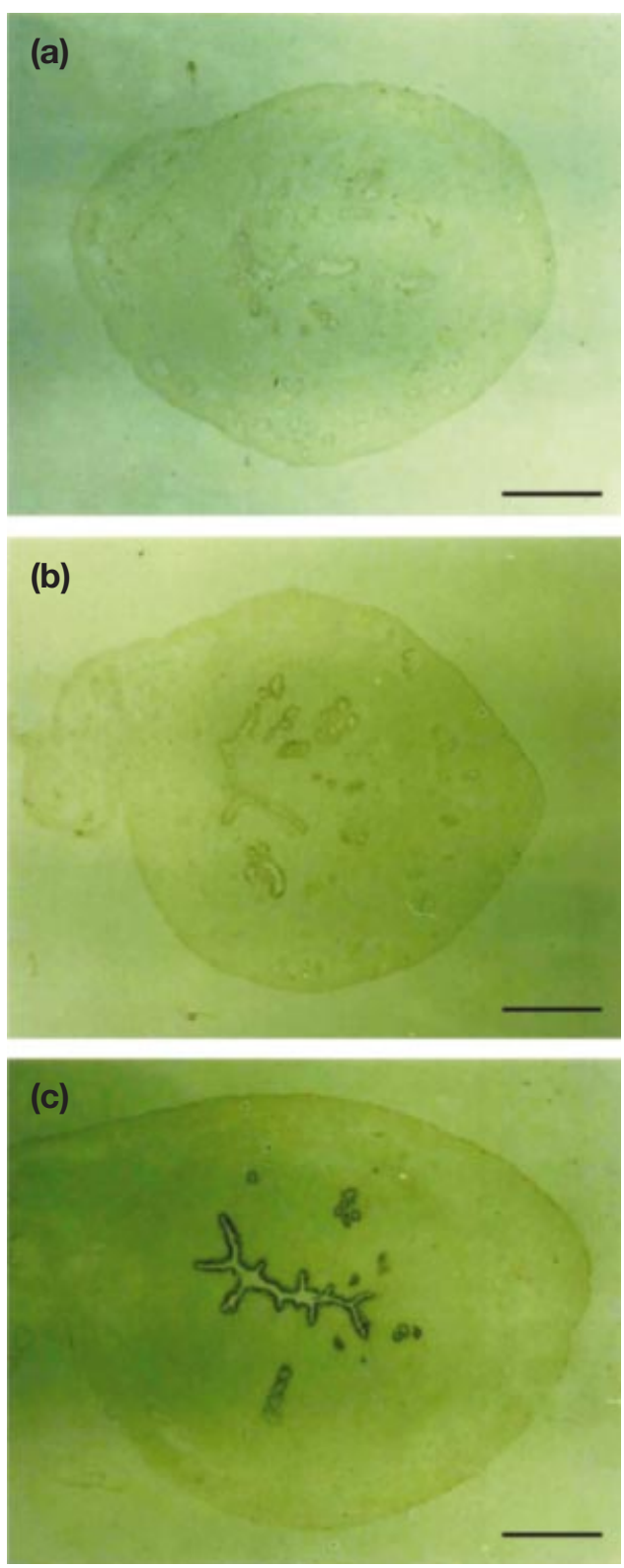

Fig. 4. Hormonal regulation of (a) basigin expression in the uterus of ovariectomized rats. (a) Basigin mRNA signal was not observed in the uterus of ovariectomized rats. (b) Basal expression of basigin mRNA was observed in the glandular epithelium after progesterone treatment. (c) Expression of basigin was induced strongly in the luminal and glandular epithelia after oestrogen treatment. Scale bars represent $25 \mu \mathrm{m}$.

\section{Discussion}

In the present study, both basigin mRNA and protein were highly expressed in the implanting blastocyst, the luminal epithelium and underlying stroma at the implantation site on day 6 of pregnancy in rats. This pattern of expression was very similar to that in the mouse uterus. Basigin mRNA expression in the mouse uterus increases transiently during early pregnancy and a peak is observed at about day 4.5 after mating, when implantation takes place. Basigin expression in the endometrium is much stronger at implantation sites than in the inter-implantation area (Kuno et al., 1998). In the present study, basigin mRNA was also detected strongly in the implanting blastocyst, in the luminal epithelium and underlying stroma, and in the glandular epithelium after delayed implantation was terminated by oestrogen treatment and the embryos implanted, whereas only a basal amount of basigin mRNA was observed in the luminal epithelium during delayed implantation. In addition, although basigin expression in the rat uterus was very similar on days 1 and 2 between early pregnancy and pseudopregnancy, only basal expression of basigin was observed in the luminal and glandular epithelium on day 6 of pseudopregnancy. The strong expression of basigin in the implantation site and decidual cells indicates that basigin might play an important role during implantation and decidualization in rats. Igakura et al. (1998) reported that most basigin null mouse embryos died at about the time of implantation, although basigin-deficient mouse embryos developed normally during preimplantation stages.

In ovariectomized rats in the present study, basigin expression was not detected in the uterus. Oestrogen significantly induced basigin expression in the luminal and glandular epithelium, whereas progesterone induced only low expression of basigin in the glandular epithelium. These findings indicate that basigin expression was also upregulated by maternal oestrogen. In mice, the pattern of basigin expression during the preimplantation period and its regulation by maternal oestrogen were similar to those for leukaemia inhibitory factor (LIF) (Kuno et al., 1998). Both LIF mRNA and protein were expressed strongly in the mouse uterus at oestrus and on day 4 of pregnancy, which just precedes blastocyst implantation (Bhatt et al., 1991; Shen and Leder, 1992; Yang et al., 1995). LIF expression was also upregulated by oestrogen in ovariectomized mice (Stewart et al., 1992; Yang et al., 1996). LIF is essential for mouse implantation in the LIF mutation model (Stewart et al., 1992). Whether there is an interaction between LIF and basigin remains to be determined.

Although basigin was expressed specifically in the rat uterus during embryo implantation and decidualization, whether basigin acts through binding to its receptors or to other molecules is unclear. Basigin can form homooligomers in a cis-dependent manner on the plasma membrane. If the disulphide bond of the more $\mathrm{N}$-terminally located Ig-like domain was destroyed by mutation, basigin could not form oligomers (Yoshida et al., 2000). Thus it seems likely that the $\mathrm{N}$-terminal Ig-like domain is necessary and sufficient for oligomer formation by basigin on the plasma membrane. Anti-basigin antibody $8 \mathrm{G} 6$ and recombinant basigin-Fc fusion protein markedly inhibit not only homophilic interaction but also the production of secreted matrix metalloproteinase 2 (MMP-2) by breast cancer cell line MDA-435 and the MMP-2-dependent invasion of MDA-435 cells through reconstituted basement membrane Matrigel (Sun and Hemler, 2001). Basigin on the surface of 
trophectoderm cells may interact with basigin on the surface of the uterine endometrium via homophilic interaction to induce the production of MMPs and to initiate embryo implantation. In addition, basigin can bind integrins ( $\alpha 3 \beta 1$ and $\alpha 6 \beta 1$ ) to form basigin-integrin complexes in the plasma membrane of the fibrosarcoma cell line (Berditchevski et al., 1997). $\alpha v \beta 3$ integrin is expressed in mouse endometrium and blastocysts at the time of implantation (Illera et al., 2000). Whether basigin in the mouse embryo and uterus is associated with embryonic and endometrial $\alpha v \beta 3$ integrin remains to be determined.

In the present study, the localization of basigin mRNA in rat embryos and decidualized cells on days 6-8 of pregnancy was consistent with a study in mice (Igakura et al., 1998). Although basigin protein was detected in the primary decidual zone on day 6 of pregnancy, basigin protein was barely detectable in the decidua on days 7 and 8 of pregnancy, which differed from the expression of basigin mRNA in the decidua. The difference between the expression of basigin mRNA and protein was also apparent on day 1 of pregnancy. The reason for this difference is unknown; however, one possible explanation is post-transcriptional regulation of basigin expression, as basigin mRNA signal was expressed more strongly than basigin protein. However, basigin immunostaining and mRNA were both induced significantly in decidualized cells during artificial decidualization. These findings indicate that basigin may play a role during decidualization and placentation in rats.

The authors are grateful to Michael J. K. Harper for his very helpful suggestions and critical review. This work was supported by Chinese National Natural Science Foundation grants 39825120, 39730250 and 30170110 . This work was also supported by CICCR Program subproject CIG-01-64 of the CONRAD Program, Eastern Virginia Medical School, Virginia, USA. The views expressed by the authors do not necessarily reflect the views of CONRAD or CICCR.

\section{References}

Berditchevski F, Chang S, Bodorova J and Hemler ME (1997) Generation of monoclonal antibodies to integrin-associated proteins: evidence that $\alpha 3 \beta 1$ complexes with EMMPRIN/basigin/OX47/M6 Journal of Biological Chemistry 27229 174-29 180

Bhatt H, Brunet LJ and Stewart CL (1991) Uterine expression of leukemia inhibitory factor coincides with the onset of blastocyst implantation Proceedings National Academy of Sciences USA 8811 408-11 412

Fan Q-W, Yuasa S, Kuno N, Senda T, Kobayashi M, Muramatsu T and Kadomatsu K (1998) Expression of basigin, a member of the immunoglobulin superfamily, in the mouse central nervous system Neuroscience Research 30 53-63

Igakura T, Kadomatsu K, Kaname T et al. (1998) A null mutation in basigin, an immunoglobulin superfamily member, indicates its important roles in peri-implantation development and spermatogenesis Developmental Biology 194 152-165

Illera MJ, Cullinan E, Gui Y, Yuan L, Beyler SA and Lessey BA (2000) Blockade of the $\alpha v \beta 3$ integrin adversely affects implantation in the mouse Biology of Reproduction 62 1285-1290

Kennedy TG and Ross HE (1997) Temporal- and hormone-dependent changes in uterine sensitization for the decidual cell reaction and decidualization in vitro of rat endometrial stromal cells Journal of Reproduction and Fertility 109 129-136

Kuno N, Kadomatsu K, Fan Q-W, Hagihara M, Senda T, Mizutani S and Muramatsu T (1998) Female sterility in mice lacking the basigin gene, which encodes a transmembrane glycoprotein belonging to the immunoglobulin superfamily FEBS Letters 425 191-194

Miyauchi T, Kanukura T, Yamaoka A, Ozawa M, Miyazawa S and Muramatsu T (1990) Basigin, a new, broadly distributed member of the immunoglobulin superfamily, has strong homology with both the immunoglobulin $\mathrm{V}$ domain and the $\beta$-chain of major histocompatibility complex class II antigen Journal of Biochemistry 107 316-323

Orlando-Mathur CE, Bechberger JF, Goldberg GS, Naus CCG, Kidder GM and Kennedy TG (1996) Rat endometrial stromal cells express the gap junction genes connexins 26 and 43 and form functional gap junctions during in vitro decidualization Biology of Reproduction 54 905-913

Shen MM and Leder P (1992) Leukemia inhibitory factor is expressed by the preimplantation uterus and selectively blocks primitive ectoderm formation in vitro. Proceedings National Academy of Sciences USA 89 8240-8244

Stewart CL, Raspar P, Brunet LJ, Bhatt H, Gadi I, Kontgen F and Abbondanzo SJ (1992) Blastocyst implantation depends on maternal expression of leukemia inhibitory factor Nature 359 76-79

Sun J and Hemler ME (2001) Regulation of MMP-1 and MMP-2 production through CD147/extracellular matrix metalloproteinase inducer interactions Cancer Research $612276-2281$

Yang ZM, Le SP, Chen DB, Cota J, Siero V, Yasukawa K and Harper MJK (1995) Leukemia inhibitory factor, LIF receptor and gp130 in the mouse uterus during early pregnancy Molecular Reproduction and Development 42 407-414

Yang ZM, Chen DB, Le SP and Harper MJK (1996) Differential hormonal regulation of leukemia inhibitory factor (LIF) in rabbit and mouse uterus Molecular Reproduction and Development 43 470-476

Yoshida S, Shibata M, Yamamoto S, Hagihara M, Asai N, Takahashi M, Mizutani S, Muramatsu T and Kadomatsu K (2000) Homo-oligomer formation by basigin, an immunoglobulin superfamily member, via its $\mathrm{N}$-terminal immunoglobulin domain European Journal of Biochemistry $2674372-4378$

Received 1 January 2002

First decision 27 February 2002.

Revised manuscript received 4 April 2002.

Accepted 16 April 2002. 